\title{
Marked Increase in Sales of Erectile Dysfunction Medication During COVID-19
}

J Gen Intern Med 36(9):2912-4

DOI: $10.1007 / \mathrm{s} 11606-021-06968-2$

(C) Society of General Internal Medicine 2021

\section{INTRODUCTION}

In response to the COVID-19 pandemic, most of the USA instituted lockdowns to minimize virus spread. As a result, cohabiting couples were quarantined together for several months, whereas those who lived apart and singles were discouraged from gathering. The effects of quarantining on sexual activity have been studied, primarily by surveys, most of which found that sexual activity decreased during the pandemic. ${ }^{1-4}$ To gain insight into the effects of COVID-19 on sexual activity, we examined the trend in national sales of phosphodiesterase-5 inhibitors (PDE5-Is), a proxy for sexual activity.

\section{METHODS}

We obtained 2018-2020 National Sales Perspective data from IQVIA, which contains $90 \%$ of drug purchases in the USA. We extracted records for PDE5-Is, including sildenafil, tadalafil, vardenafil, and avanafil. We used as controls tamsulosin and finasteride, two widely utilized urologic treatments not indicated for erectile dysfunction, and for which we did not expect a change in consumption during COVID-19.

For each month and medication, we calculated the number of units sold. We conducted interrupted timeseries analyses to examine changes in the trend of sales after the pandemic declaration in March 2020. Regression models included a continuous variable for month, an indicator variable for the period after March 2020, and the interaction between them.

\section{RESULTS}

Before March 2020, sales of PDE-5Is increased by a monthly average of 285,653 units (Fig. 1). Sales of

Received April 5, 2021

Accepted June 4, 2021

Published online June 25, 2021
PDE5-Is decreased in the 2 months after pandemic declaration (April and May 2020), with $p$ value for level change $<0.001$. However, the trend in sales of PDE5-Is increased after the pandemic declaration (coefficient for trend change $=920,947, p$ value $<0.001$ ). As a result of this increase in trend, sales of PDE5-Is in December $2020(24,324,258$ units $)$ were $67 \%$ higher than in February $2020(14,576,724)$. This increase was driven by an $85 \%$ increase in sales of tadalafil (Fig. 2). The increase in sales of tadalafil was particularly pronounced for the $5 \mathrm{mg}$ dosage form, which is indicated for daily administration. Specifically, sales of tadalafil $5 \mathrm{mg}$ in December 2020 (10,999,040 units) doubled sales in February 2020 (5,518,560 units) (Fig. 2). Sales of control drugs, including tamsulosin and finasteride, did not significantly change after March 2020 (p values for level change $=0.469, \mathrm{p}$ value for slope change $=0.549)$ (Fig. 1).

\section{DISCUSSION}

Since the pandemic, nationwide sales of PDE5-Is increased significantly, while the sale of other urologic medications remained constant. Increases in sales were more pronounced for daily tadalafil formulations than on-demand formulations.

Our findings suggest that, at least for some men, sexual activity increased during the pandemic. Our results may differ from previous surveys reporting decreased sexual activity because of differences in patient populations. While PDE5-Is are indicated in men with erectile dysfunction, previous surveys consisted primarily of cohabitating couples, men under the age of 40 , and women of reproductive age. ${ }^{1-3}$ These couples are more likely to have children, which was associated with decreased sexual activity in two surveys. ${ }^{2,3}$ However, men with erectile dysfunction who take PDE5-Is may represent a population less likely to have children at home and with more leisure time and privacy. The increase predominately in tadalafil $5 \mathrm{mg}$ may suggest a preference for spontaneity and flexibility for the timing of sexual encounters in the pandemic setting. While for some COVID-19 has been an obstacle to sexual activity, for others it has provided more opportunity.

Our findings using nationwide sales data demonstrate that the COVID epoch has triggered a large increase in sales of PDE5-Is. 


\section{A PDE5 Inhibitors}

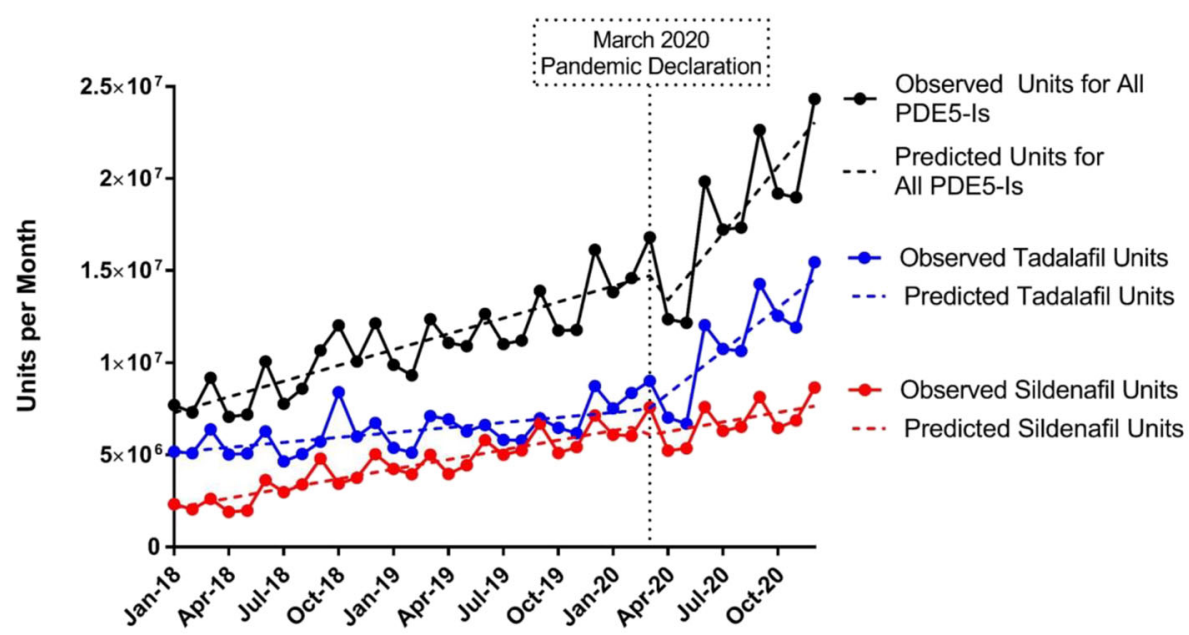

B Controls

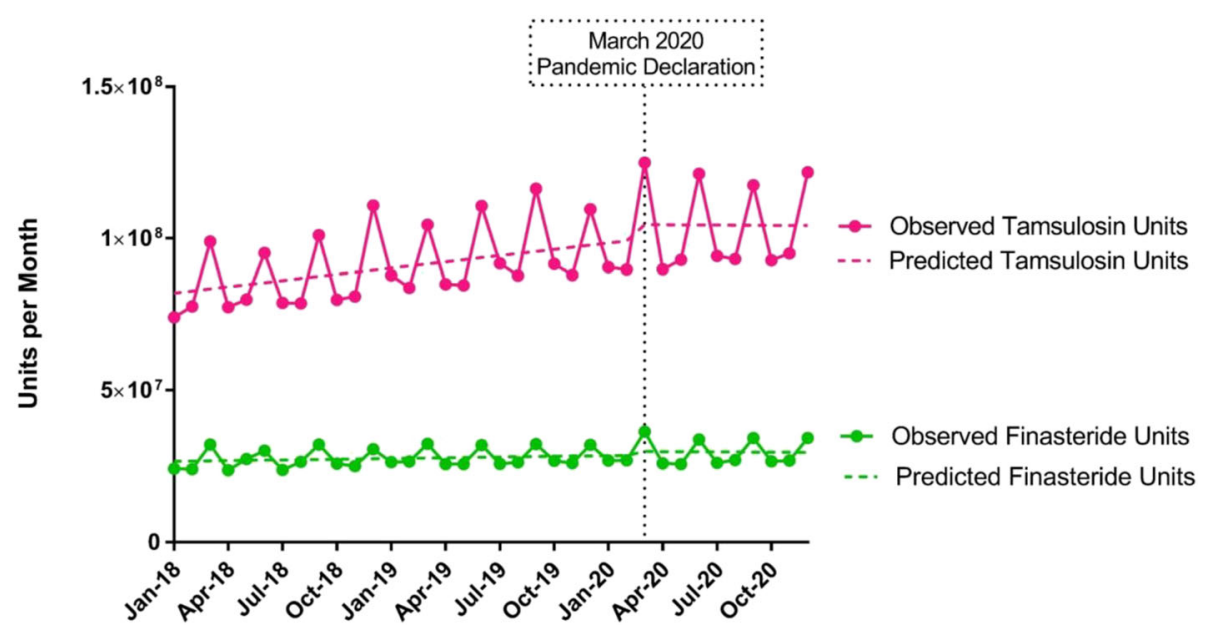

Fig. 1 Trends in monthly sales, January 2018-December 2020. PDE5-Is, phosphodiesterase-5 inhibitors. The figure shows the number of units sold in the retail setting per month for PDE5-Is (upper panel) and control drugs (lower panel). Cross marks indicate observed number of units; solid lines indicated units predicted with interrupted time-series analyses. PDE5-Is include units for sildenafil, tadalafil, vardenafil, and avanafil. Vardenafil and avanafil units were not shown separately because their low utilization made the data series indistinguishable from the $x$-axis. 


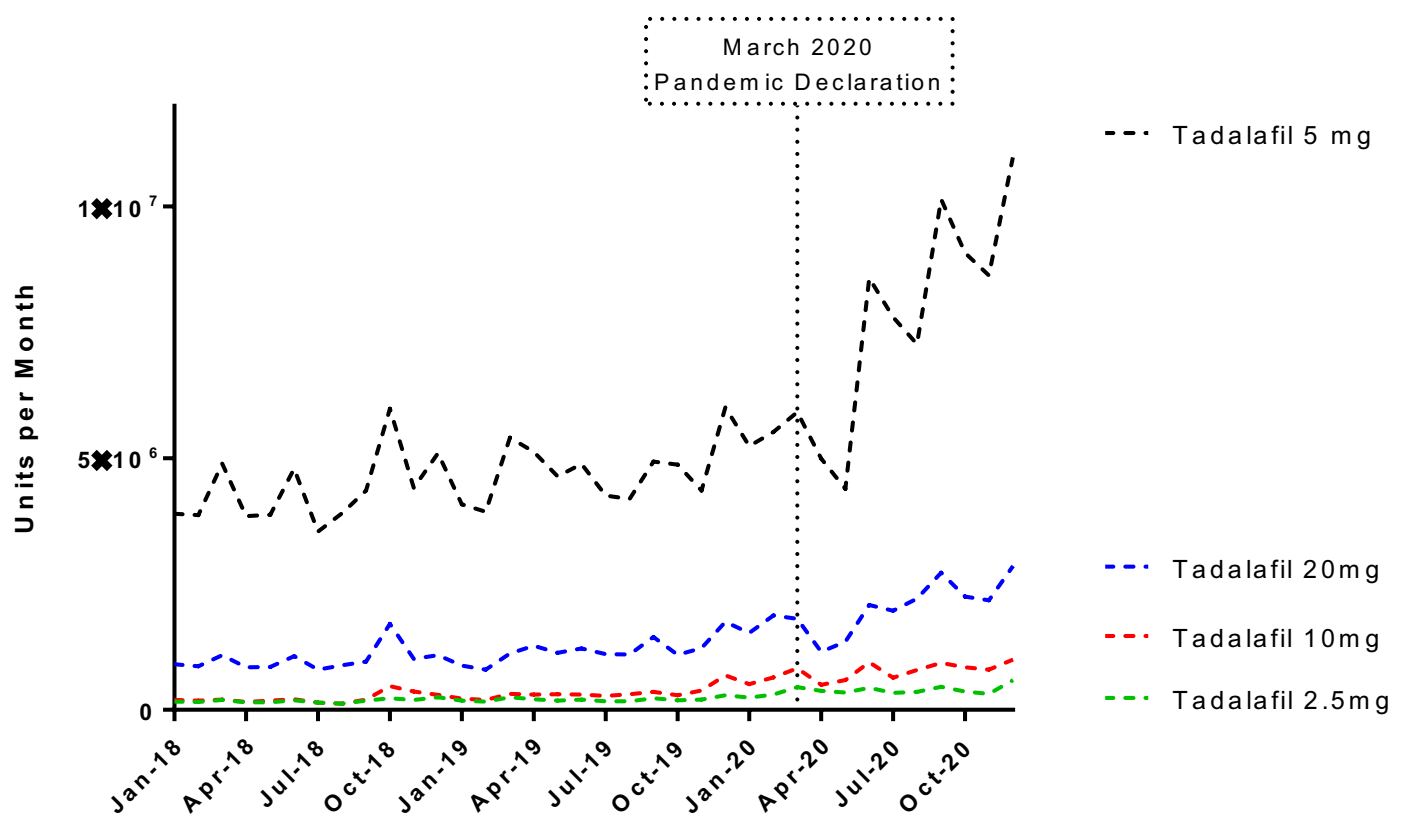

Fig. 2 Observed trends in monthly sales of tadalafil, by dose. The figure shows the number of units sold per month for each dose of tadalafil.

Inmaculada Hernandez, PharmD, $P h D^{1}$

Zeynep Gul, $M D^{2}$

Walid F. Gellad, MD, $M P H^{3}$

Benjamin J. Davies, $M D^{2}$

${ }^{1}$ Division of Clinical Pharmacy, University of

California, San Diego,

La Jolla, CA, USA

${ }^{2}$ Department of Urology, UPMC,

Pittsburgh, PA, USA

${ }^{3}$ Division of General Internal Medicine, University of

Pittsburgh School of Medicine,

Pittsburgh, PA, USA

Corresponding Author: Inmaculada Hernandez, PharmD, PhD; Division of Clinical Pharmacy, University of California, San Diego, La Jolla, CA, USA (e-mail: inhernandez@health.ucsd.edu).

Funding Hernandez is funded by the National Heart, Lung and Blood Institute (grant number KO1HL142847).

\section{Declarations:}

Conflict of Interest: Hernandez has received consulting fees from Pfizer and has participated in a scientific advisory board, also for Pfizer, outside of the submitted work.

\section{REFERENCES}

1. Karagöz MA, Gül A, Borg C, Erihan İB, Uslu M, Ezer M, Erbağcı A, Çatak B, Bağcıŏlu M. Influence of COVID-19 pandemic on sexuality: a cross-sectional study among couples in Turkey. Int J Impot Res 2020.

2. Schiavi MC, Spina V, Zullo MA, Colagiovanni V, Luffarelli P, Rago R, Palazzetti P. Love in the time of COVID-19: sexual function and quality of life analysis during the social distancing measures in a group of Italian reproductive-age women. J Sex Med 2020;17:1407-1413.

3. Cito G, Micelli E, Cocci A, Polloni G, Russo GI, Coccia ME, Simoncini T, Carini M, Minervini A, Natali A. The impact of the COVID-19 quarantine on sexual life in Italy. Urology 2021;147:37-42.

4. Li G, Tang D, Song B, Wang C, Gunshan S, Xu C, Geng H, Wu H, He X, Cao Y. Impact of the COVID-19 pandemic on partner relationships and sexual and reproductive health: cross-sectional, online survey study. $J$ Med Internet Res 2020;22.

Publisher's Note: Springer Nature remains neutral with regard to jurisdictional claims in published maps and institutional affiliations. 